\title{
Robotics in urology: A short review and a single-centre experience with Senhance ${ }^{\mathrm{TM}}$ robotics system
}

\author{
Tvrtko Hudolin ${ }^{1,2}$, Tomislav Kuliš ${ }^{1,2}$, Nikola Knežević ${ }^{1,2}$, Luka Penezić ${ }^{1}$, Toni Zekulić1, \\ Dinko Hauptman ${ }^{1}$, Hrvoje Sajić ${ }^{1}, \check{Z Z e l j k o ~ K a s ̌ t e l a n ~}^{1,2}$ \\ ${ }^{1}$ University hospital centre Zagreb, Department of urology \\ 2 The University of Zagreb, Faculty of Medicine
}

OPEN ACCESS

Correspondence: Tvrtko Hudolin thudolin@gmail.com orcid.org/0000-0002-6658-2344

This article was submitted to RAD CASA - Medical Sciences as the original article

Conflict of Interest Statement: The authors declare that the research was conducted in the absence of any commercial or financial relationships that could be construed as a potential conflict of interest.

Received: 26 March 2021 Accepted: 28 April 2021 Published: 15 June 2021

Citation: Hudolin T, Kuliš T, Knežević N, Penezić L, Zekulić T, Hauptman D, Sajić H, Kaštelan Z. Robotics in urology: A short review and a single-centre experience with Senhance ${ }^{\mathrm{TM}}$ robotics system RAD CASA - Medical Sciences. 547=54-55 (2021): 64-68 DOI: https://dx.doi.org/10.21857/

Copyright (C) 2021 Hudolin T, Kuliš T, Knežević N, Penezić L, Zekulić T, Hauptman D, Sajić H, Kaštelan Z. This is an open-access article distributed under the terms of the Creative Commons Attribution License (CC BY). The use, distribution or reproduction in other forums is permitted, provided the original author(s) and the copyright owners(s) are credited and that the original publication in this journal is cited, in accordance whit accepted dacemic practice. No use distribution or reproduction is use, distribution or reproduction is permitted which
does not comply with these terms.

\section{ABSTRACT:}

Robotic surgery was introduced into urology 20 years ago. Since then, it has gradually become the gold standard for many surgeries, especially for radical prostatectomy. Until recently, the only available and widespread used robotic platform was the da Vinci robotic system. Today, new platforms are emerging. One of these platforms is Senhance ${ }^{\mathrm{TM}}$ robotic system, approved by FDA, and used in several European and world urological centres. In this short review, we present our standpoints about robotics in urology and our two-year experience with the Senhance ${ }^{\mathrm{TM}}$.

KEYWORDS: robotics; prostatectomy; prostate cancer; urology

\section{SAŽETAK:}

Robotika u UROLOGIJI: KRATKI PREGLED I ISKUSTVO NAŠEg CENTRA SA SENHANCE ${ }^{\mathrm{TM}}$ ROBOTSKIM SUSTAVOM Robotika je uvedena u urologiju prije 20 godina. Od tada je postupno postala zlatni standard za mnoge operacije, osobito za radikalnu prostatektomiju. Donedavno je robotski sustav da Vinci bio jedini $\mathrm{u}$ širokoj upotrebi, ali danas postoje i druge robotske platforme. Jedna od njih je Senhance ${ }^{\mathrm{TM}}$ robotski sustav, koji je odobren od Američke Agencije za hranu i lijekove i koji se koristi u nekoliko europskih i svjetskih uroloških centara. U ovom kratkom pregledu predstavljamo robotsku radikalnu prostatektomiju i naše dvogodišnje iskustvo sa Senhance ${ }^{\mathrm{TM}}$ platformom.

KLJUČNE RIJEČI: robotika; prostatektomija; rak prostate; urologija 
It has been more than 20 years since the introduction of robotic surgery in urology. The first robotic platform approved by the Food and Drug Administration (FDA) for urologic surgery was da Vinci surgical system from Intuitive Surgical (Sunnyvale, US). In a relatively short period of time it has become a golden standard for many urological operations, especially in the United States.

Robotic surgery, which had a foundation in laparoscopy, was a step forward, offering several important advantages over conventional, open surgery, but also compared to laparoscopy itself. This minimally invasive approach offered significantly reduced morbidity, improved postoperative recovery, and reduced hospital stay, but with increased costs mainly due to the purchase and maintenance of the platform, but also due to instruments that cannot be reused. In this review article, we will present the past, present, and future of robotic-assisted radical prostatectomy (RARP), as well as our experiences with this new and exciting method.

The Robotic era began in 1999 with the development and introduction of the da Vinci robotic platform for cardiac surgery, soon entering many different surgical fields, including urology ${ }^{1}$ Although there are many urological procedures today that can be performed robotically, RARP is the most common and most important. RARP is considered the gold standard for patients with localized prostate cancer who are generally in good health and with a life expectancy of more than 10 years ${ }^{2}$. This operation can cure many patients, but it also carries a significant risk for different morbidities, including a reduction or even deprivation of some very important urological and sexual functions, which greatly reduces the quality of life for a significant number of patients.

There are three main goals of RARP, the so-called trifecta: cancer free, continent, and potent patients ${ }^{3,4}$. To achieve these goals, urologists are in a continuous search for improvement of anatomical knowledge and surgical technique, but also the application of new techniques available today. Over a 50-year period, RARP evolved from the open approach, first introduced by Terrance Millin in 1947, to the laparoscopic approach first described by WW Schuessler in 1991 and finally to the robotic RARP in 2000 by CC Abbou ${ }^{5-7}$.

The laparoscopic approach introduced several very important advantages over open radical prostatectomy (RP) such as better visualization, reduced blood loss, shorter incision length, less wound infection, less postoperative pain, shorter hospitalization and better cosmetic results, but also some important weaknesses like loss of haptic feedback and natural eye-hand coordination. Robotic surgery was introduced to improve the laparoscopic approach and overcome some of its limitations ${ }^{8}$. Since the initial report, there has been a steady increase in the number of RARP and it is estimated that in 2020 about $80 \%$ of all radical prostatectomies in the USA will be done using robotics ${ }^{1}$.
With the introduction of minimally invasive approaches such as laparoscopy or robotic surgery, improved oncological and functional outcomes were expected. These new approaches offered better visualization of important deep pelvic anatomical structures, responsible for maintaining potency and continence, with a neurovascular bundle as one of the most important.

There are many studies describing RARP and comparing it to open and laparoscopic approaches, but many of them are actually limited by the retrospective nature, the relatively small number of patients, the experience of single institution and/or single surgeon. However, those who had a better study design, showed in general that RARP offers the same or better functional outcomes compared to laparoscopy, especially compared to open RP. Furthermore, the robotic approach significantly reduced blood loss, complication rates and hospital stay ${ }^{9-13}$. However, it is important to note that, when assessing the trifecta outcomes, the results seem to be highly surgeon dependent and in relation to his education, skills and experience ${ }^{13}$.

One important drawback of RARP is that long-term oncological results are still missing due to being the newest surgical approach. Another important drawback for robotic surgery is the cost of the procedure, which includes the cost of purchasing and maintaining the robot, as well the cost of the single-use instruments. These expenses are high, especially for middle- and low-income countries, since the cost of a da Vinci surgical system is approximately $2.5 \mathrm{mil}$. US dollars, increased by the cost of start-up reusable equipment and accessories by an additional 200 000 dollars, an annual maintenance which cost 175000 dollars/ year, and for the price of disposables and consumables (per procedure) of 2500 dollars ${ }^{14}$. These high costs can be justified by significantly shorter postoperative hospitalisation, less blood loss, i.e. the need for transfusion and faster recovery of the patient. Furthermore, RARP has been shown to provide cost savings (depending on the perspective) for the treatment of prostate cancer in the healthcare system ${ }^{15}$. There are no studies that can give us a definitive answer as to which method is better. The question is whether these studies can be performed at all, with all the questions and the limitations associated with this type of research are taken into account.

There is also another important question: which technique should a urologist learn? Is it better to start with open, followed by laparoscopic and then RARP, or can we skip the open or laparoscopic approach and move straight to robotic surgery because it is becoming the dominant form of RP, at least in the Western world? It is also important to know how long the learning curve is and how many cases should be performed to gain sufficient proficiency? It is not easy to answer these questions, but we can say that a urologist today must know all three methods for at least two important reasons. The first is the need for conversion 
from robotic to laparoscopic or open surgery, when required. The second is the fact that, although the approach and equipment used in different types of radical prostatectomies are different, the surgical anatomy is the same, and with more experience gained from all three approaches, you will be a better surgeon, i.e. robotic surgeon.

It has been shown that the learning curve of robotic RARP is shorter compared to laparoscopic RARP and that fewer cases are required to acquire sufficient knowledge ${ }^{16,17}$. To help robotic surgeons, many companies provide training for urologists, from e-learning and simulation training to dry and wet labs, where surgeons mimic real conditions using animals or human corpses. Moreover, some manufacturers require surgeons to go through all these steps in order to become familiar with the technique and obtain the necessary certification for its use ${ }^{1}$.

There are many robotic surgical platforms in development around the world, but only a few are approved for commercial use. The Senhance ${ }^{\mathrm{TM}}$ was the first platform approved by FDA since da Vinci. The Versius ${ }^{\mathrm{TM}}$ (CMR Surgical, Cambridge, UK) is awaiting FDA approval, but has CE mark approval, and there are reports of successful clinical colorectal surgery and preclinical urologic surgery ${ }^{18,19}$. The REVO-I system (Meere Company Inc., Yongin, Korea) approved in Korea, has been successfully utilized for Retzius-sparing robot-assisted radical prostatectomy in 17 patients in $2018{ }^{20}$. Another system, the Avatera ${ }^{\mathrm{TM}}$ (Avateramedical GmbH, Jena, Germany) has recently been CE mark approved and we can expect clinical results soon. The field of robotic-assisted surgery is growing fast and novel systems are emerging, however, except for the well-known da Vinci system, the only one in a more widespread clinical use in urology is the Senhance $^{\mathrm{TM}}$ robotic system ${ }^{21-23}$.

\section{OUR EXPERIENCE}

In 2018 we acquired the Senhance ${ }^{\mathrm{TM}}$ robotic platform approved by the FDA a year earlier for various surgical procedures, including urological (Figure 1, 2, 3.). This new platform is starting to be used in a number of institutions, mainly in Europe ${ }^{24,25}$. After the initial training provided by the company, we started with the robotic adrenalectomy and renal surgery. Since November 2019 we have been performing RARP and are approaching the first 100 cases. The Senhance ${ }^{\mathrm{TM}}$ robotic platform was our first robotic platform and we had no previous experience with robotic surgery, but we had extensive experience in the open and solid experience with laparoscopic RP. We have published our technique and initial results and we can state that RARP with Senhance $^{\mathrm{TM}}$ platform is a feasible and safe procedure, with acceptable functional and oncological results and with significantly reduced costs compared to the da Vinci, mostly due to the use of reusable instruments ${ }^{22,23}$. Although a real comparison with the da Vinci system could only be possible if we had both systems, a

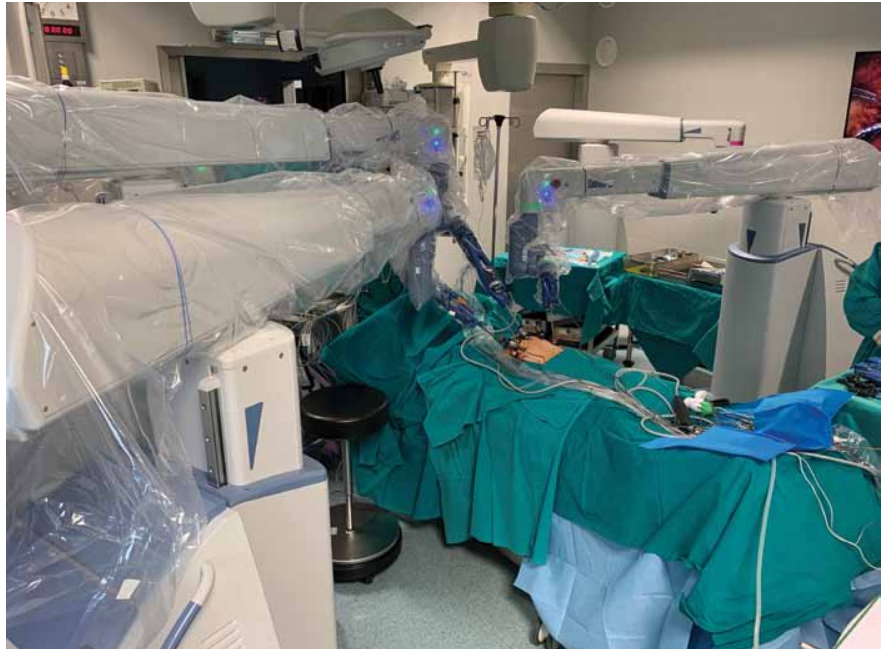

Figure 1. Robotic setting in the operating theatre. There are three robotic hands controlled by the operator. One is holding the camera and the other two are holding instruments. Additional trocars are used for laparoscopic instruments controlled by assistant surgeons.

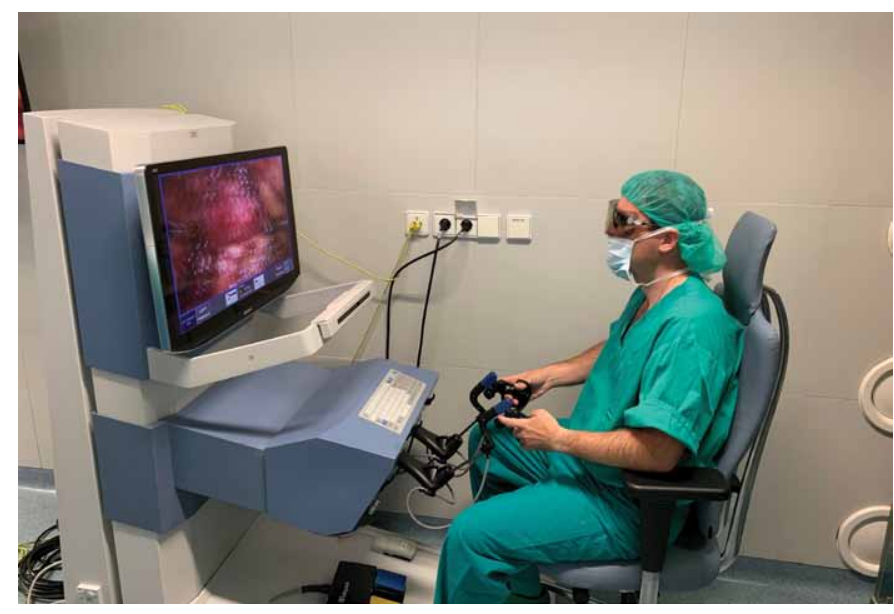

Figure 2. The position of surgeon at the operating console. Camera is controlled with the eye tracking technology, while the other two robotic hands are controlled with the laparoscopy-mimicking instrument handles. The console is equipped with haptic feedback and ultra-high-definition $3 D$ screen.

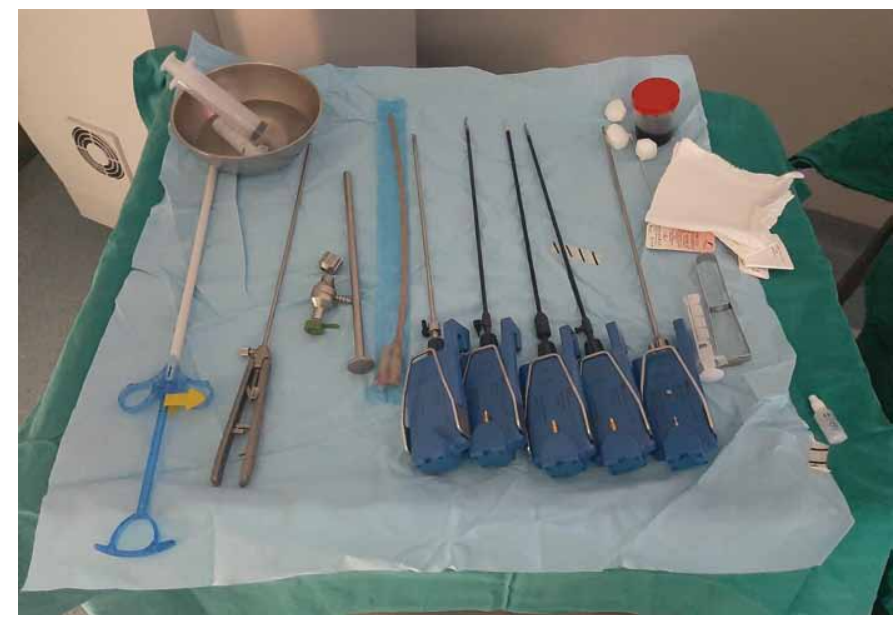

Figure 3. Robotic instruments. From left to right: needle holder, scissors, monopolar hook, monopolar grasper, bipolar grasper. 
comparison based on data from the literature and our experience shows that the price of instruments is significantly lower than the da Vinci system due to the use of reusable instruments. In addition to significant cost reductions, Senhance ${ }^{\mathrm{TM}}$ offers additional new benefits such as eye tracking technology, haptic feedback, and a comfortable sitting position that are also important benefits. Such robotic platforms are a very good option for institutions and countries that have limited financial resources, but also want to offer their patients new minimally invasive procedures that were not available before, or for which they had to go abroad.

\section{CONCLUSION}

With increasing experience, we expect to further improve results regarding morbidity, operative time, hospital stay and functional as well as oncological results. Although da Vinci is still the most common surgical platform, there are new robotic systems which are already available or will be soon. The competition will bring technical improvement, cost reduction and enable wider use of RARP as shown in our case, all for the benefit of the patients. 


\section{REFERENCES:}

1. McGuinness LA, Prasad Rai B. Robotics in urology. Annals of the Royal College of Surgeons of England. 2018;100(6_ sup):38-44.

2. Carlucci JR, Nabizada-Pace F, Samadi DB. Robot-assisted laparoscopic radical prostatectomy: technique and outcomes of 700 cases. Int J Biomed Sci. 2009;5(3):201-8.

3. Borregales LD, Berg WT, Tal O, Wambi C, Kaufman S, Gaya JM, et al. 'Trifecta' after radical prostatectomy: is there a standard definition? BJU international. 2013;112(1):60-7.

4. Shikanov SA, Zorn KC, Zagaja GP, Shalhav AL. Trifecta outcomes after robotic-assisted laparoscopic prostatectomy. Urology. 2009;74(3):619-23.

5. Millin T. Retropubic prostatectomy; a new extravesical technique; report of 20 cases. Lancet (London, England). 1945;2(6380):693-6.

6. Schuessler WW, Schulam PG, Clayman RV, Kavoussi LR. Laparoscopic radical prostatectomy: initial short-term experience. Urology. 1997;50(6):854-7.

7. Abbou CC, Hoznek A, Salomon L, Olsson LE, Lobontiu A, Saint F, et al. Laparoscopic radical prostatectomy with a remote controlled robot. The Journal of urology. 2001;165(6 Pt 1):1964-6.

8. Sood A, Jeong W, Peabody JO, Hemal AK, Menon M. Robot-assisted radical prostatectomy: inching toward gold standard. The Urologic clinics of North America. 2014;41(4):473-84.

9. Asimakopoulos AD, Pereira Fraga CT, Annino F, Pasqualetti P, Calado AA, Mugnier C. Randomized comparison between laparoscopic and robot-assisted nerve-sparing radical prostatectomy. The journal of sexual medicine. 2011;8(5):1503-12.

10. Porpiglia F, Morra I, Lucci Chiarissi M, Manfredi M, Mele F, Grande S, et al. Randomised controlled trial comparing laparoscopic and robot-assisted radical prostatectomy. European urology. 2013;63(4):606-14.

11. Trinh QD, Sammon J, Sun M, Ravi P, Ghani KR, Bianchi $\mathrm{M}$, et al. Perioperative outcomes of robot-assisted radical prostatectomy compared with open radical prostatectomy: results from the nationwide inpatient sample. European urology. 2012;61(4):679-85.

12. Ilic D, Evans SM, Allan CA, Jung JH, Murphy D, Frydenberg M. Laparoscopic and robot-assisted vs open radical prostatectomy for the treatment of localized prostate cancer: a Cochrane systematic review. BJU international. 2018;121(6):845-53.

13. Robertson C, Close A, Fraser C, Gurung T, Jia X, Sharma $P$, et al. Relative effectiveness of robot-assisted and standard laparoscopic prostatectomy as alternatives to open radical prostatectomy for treatment of localised prostate cancer: a systematic review and mixed treatment comparison metaanalysis. BJU international. 2013;112(6):798-812.
14. Ho C, Tsakonas E, Tran K, Cimon K, Severn M, Mierzwinski-Urban M, et al. CADTH Health Technology Assessments. Robot-Assisted Surgery Compared with Open Surgery and Laparoscopic Surgery: Clinical Effectiveness and Economic Analyses. Ottawa (ON): Canadian Agency for Drugs and Technologies in Health Copyright (C) CADTH September 2011.; 2011.

15. Bijlani A, Hebert AE, Davitian M, May H, Speers M, Leung $\mathrm{R}$, et al. A Multidimensional Analysis of Prostate Surgery Costs in the United States: Robotic-Assisted versus Retropubic Radical Prostatectomy. Value in Health. 2016;19(4):391-403.

16. Amodeo A, Linares Quevedo A, Joseph JV, Belgrano E, Patel HR. Robotic laparoscopic surgery: cost and training. Minerva urologica e nefrologica $=$ The Italian journal of urology and nephrology. 2009;61(2):121-8.

17. Ahlering TE, Skarecky D, Lee D, Clayman RV. Successful transfer of open surgical skills to a laparoscopic environment using a robotic interface: initial experience with laparoscopic radical prostatectomy. The Journal of urology. 2003;170(5):1738-41.

18. Collins D, Paterson HM, Skipworth RJE, Speake D. Implementation of the Versius robotic surgical system for colorectal cancer surgery: First clinical experience. Colorectal Disease. 2021;n/a(n/a).

19. Thomas BC, Slack M, Hussain M, Barber N, Pradhan A, Dinneen E, et al. Preclinical Evaluation of the Versius Surgical System, a New Robot-assisted Surgical Device for Use in Minimal Access Renal and Prostate Surgery. European urology focus. 2020.

20. Chang KD, Abdel Raheem A, Choi YD, Chung BH, Rha KH. Retzius-sparing robot-assisted radical prostatectomy using the Revo-i robotic surgical system: surgical technique and results of the first human trial. BJU international. 2018;122(3):441-8.

21. Koukourikis P, Rha KH. Robotic surgical systems in urology: What is currently available? Investig Clin Urol. 2021;62(1):14-22.

22. Kaštelan Ž, Knežević N, Hudolin T, Kuliš T, Penezić L, Goluža E, et al. Extraperitoneal radical prostatectomy with the Senhance Surgical System robotic platform. Croat Med J. 2019;60(6):556-9.

23. Kastelan Z, Hudolin T, Kulis T, Penezic L, Gidaro S, Bakula M, et al. Extraperitoneal Radical Prostatectomy with the Senhance Robotic Platform: First 40 Cases. European urology. 2020;78(6):932-4.

24. deBeche-Adams T, Eubanks WS, de la Fuente SG. Early experience with the Senhance-laparoscopic/robotic platform in the US. Journal of robotic surgery. 2019;13(2):357-9.

25. Samalavicius N, Janusonis V, Siaulys R, Jasėnas M, Deduchovas O, Venckus R, et al. Robotic surgery using Senhance ${ }^{\oplus}$ robotic platform: single center experience with first 100 cases. Journal of robotic surgery. 2020;14. 
